ORIGINAL ARTICLE

\title{
Physical Therapists' Perception and Educational Opportunities to Improve Exercise Adherence in Older Patients and Clients: A Qualitative Study
}

\author{
Takashi Ariie, RPT, MSc ${ }^{\text {a,b }}$ Masami Nakahara, RPT, MSc ${ }^{a}$ and Masaharu Morita, RPT, PhD ${ }^{c}$
}

Objectives: The aim of the study was to understand the physical therapist's experience and perception of the support they give to their older patients or clients to continue exercising. Methods: Using purposive sampling, we recruited fifteen physical therapists with more than 5 years of clinical experience and conducted semi-structured interviews. We analyzed the transcribed data using thematic analysis. Results: Three main themes emerged: (1) the expected results as healthcare professionals, (2) clinical experience and continuing professional development, and (3) limited educational opportunities. Physical therapists struggled to achieve a certain level of exercise adherence in their patients, and the low success rate decreased their confidence. We found that physical therapists needed not only to rely on clinical experience but also to integrate scientific evidence to implement better behavioral change techniques; they would also appreciate receiving appropriate educational opportunities. Conclusions: This study revealed a possibility of educational insufficiency for physical therapist to support of behavior change to improve exercise adherence in the older population.

Key words : behavior change; education; exercise adherence; physical therapist; qualitative study

\section{INTRODUCTION}

Exercise is essential to maintain and improve our health, but difficulty in maintaining a regular regimen can lead to physical inactivity. Physical activity insufficiency is a global problem $^{1)}$ that should be addressed, especially in the older population because such insufficiency increases the risk of hospitalization and multimorbidity. ${ }^{2)}$ For older patients and clients, hospitalization is associated with decreased physical function, ${ }^{3)}$ which likely results from a lack of physical activity. Although regular exercise in older people may provide physical and psychological benefits, ${ }^{4,5)}$ irregular adherence rates have been reported. ${ }^{6}$ Despite the detrimental effects of physical inactivity and the importance of regular physical activity, there are many obstacles to the continuation of exercising.

Many interventions to improve exercise adherence have been investigated, but their long-term efficacy has not been established. A previous systematic review identified strategies to increase exercise adherence in older adults, including the use of technologies such as telecommunication, exergaming, and computer feedback training. $\left.{ }^{6}\right)$ In particular, behavioral change techniques are often used by healthcare workers, including physical therapists, to improve exercise adherence. ${ }^{7,8)}$ However, a recent systematic review concluded

Received: October 26, 2020, Accepted: January 6, 2021, Published online: January 27, 2021

${ }^{a}$ Department of Physical Therapy, School of Health Sciences at Fukuoka, International University of Health and Welfare, Fukuoka, Japan

${ }^{\mathrm{b}}$ Division of Physical Therapy, Doctoral Program in Health Sciences, Graduate School of Health and Welfare Sciences, International University of Health and Welfare, Fukuoka, Japan

c Department of Physical Therapy, School of Health Sciences at Odawara, International University of Health and Welfare, Kanagawa, Japan

Correspondence: Takashi Ariie, RPT, MSc, Department of Physical Therapy, School of Health Sciences at Fukuoka, International University of Health and Welfare, 137-1 Enokizu, Okawa-shi, Fukuoka 831-8501, Japan, E-mail: tariie@iuhw.ac.jp

Copyright (C) 2021 The Japanese Association of Rehabilitation Medicine

This is an open-access article distributed under the terms of the Creative Commons Attribution Non-Commercial No Derivatives (CC BY-NC-ND) 4.0 License. http://creativecommons.org/licenses/by-nc-nd/4.0/ 
that behavioral change interventions performed by physical therapists do not produce effective long-term outcomes.9) Although the development of behavioral change techniques can promote physical activity adherence, research does not provide adequate or robust evidence of long-term efficacy.

Techniques to bring about behavioral change are important tools for healthcare professionals because they are used to support patients. ${ }^{10)}$ A previous study on primary care practitioners identified that skepticism of the effectiveness of behavior change interventions and the lack of available evidence constituted barriers to behavior change support. ${ }^{11)}$ Another study reported that the confidence of primary care physicians in their ability to change behavior was varied. ${ }^{12)}$ Lack of knowledge and training regarding behavior change have also been identified as barriers to physical activity promotion. ${ }^{12)}$ However, provider's reports are still sparse, in particular among physical therapists. Physical therapists prescribe exercise therapy, and it is their role to promote it in their daily practice. ${ }^{13,14)}$ In-depth understanding of the clinician's perspective can be important to develop more effective behavior change approaches to support exercise adherence in older populations.

The purpose of the current study was to understand the experience and perception of physical therapists relating to the support they provide to promote older patients and clients to continue exercising. A better understanding of the healthcare provider's experience and perspective may lead to more effective use of behavior change techniques and result in better patient outcomes. In this study, we present the results of interviews covering attitudes, confidence, and education relating to the support provided to improve exercise adherence.

\section{METHODS}

This qualitative study was conducted in accordance with the standards for reporting qualitative research. ${ }^{15)}$ We used qualitative descriptions to match the qualitative approach in this study ${ }^{16)}$ This approach is well suited to discovery of the experience of healthcare participants and to gaining insights in an inadequately understood phenomenon. We used interpretivism as a methodological orientation to understand physical therapists' experiences and perspectives in their clinical context. ${ }^{17)}$ We conducted one-on-one, semi-structured, face-to-face interviews. Interviews were conducted by one male author (TA) who has more than 5 years of clinical experience as a physical therapist and who is currently working in an educational setting. TA received training in qualitative research as part of a postgraduate course and also has knowledge of behavioral change techniques through clinical experience. Before each interview, the author wrote down his own answers to the interview questions to acknowledge his own opinions. We prepared an interview guide to ascertain the physical therapist's clinical practice to support patients' adherence to physical activity (Fig. 1). The guide was based on a previous qualitative study investigating physical activity promotion by physical therapists. ${ }^{14)} \mathrm{We}$ decided to use this study because it explored similar topics with similar participants to the current research. We modified several phrases (e.g., adding "older patients") according to the purpose of the research. One author (TA) developed the guide, and the other authors (MN, MM) revised it. Before the commencement of the interview with participants, the author (TA) carried out a practice interview with another author (MN) to establish timing and to practice note taking using the guide. The guide's themes included attitudes, confidence, and education.

The physical therapists included in this study: (1) were currently working in a clinical setting, (2) had more than 5 years of clinical experience, and (3) had experience working with older patients or clients. We excluded participants who could not undergo an interview in Japanese. To provide data on diverse clinical contexts, the participants were recruited from several settings, such as acute care, convalescent wards, and day services. We used purposive and snowball sampling to enroll participants because we needed to recruit participants who met specific criteria. We selected potential participants from the authors' neighboring facilities. The author (TA) knew all the participants before the study. The aim of this research was explained to the participants before the study. The sample size was considered based on previous studies ${ }^{14,18)}$ relevant to this one, and we concluded that 15 physical therapists constituted an adequate number of participants to analyze our themes.

\section{Data Collection}

We conducted all the interviews on a one-to-one basis in private rooms. The interviews were audio-recorded and transcribed by TA. The planned length of each interview was about $60 \mathrm{~min}$. If the author considered that follow-up interviews were necessary to understand or further clarify the contents of interviews, the participants were interviewed a second time by telephone. We returned the transcriptions to the participants and they checked the contents. Field notes were made during interviews. Data saturation was discussed by two authors (TA and MN). 


\section{Interview Guide}

- Show the appreciation to the participants for their cooperation.

- Confirm that they have read the research proposal

- Confirm that they signed the consent form and obtain a verbal confirmation of consent again.

- Confirm the contents of this interview

-Objectives and Research Plan

-Methods usually used in clinical practice to support older patients or clients (65 years and older) to continue exercising.

-Unlimited types of exercise.

- The interview lasts about 60 minutes and is recorded.

- Remind the participants that if have any questions, they can always ask and there are no right or wrong answers.

\section{Introduction}

- What kind of workplace are you currently working in?

- How many older (65 years and older) patients or clients do you see per week?

- How many days a week do you have the opportunity to support the continuation of exercise?

\section{Attitude}

- Do you think supporting the older patients or clients to continue exercising is an important role for a physical therapist? Why is that?

\section{Confidence}

- Do you have confidence in your ability to support older patients or clients to continue exercising in your daily practice?

\section{Education for the support of behavior change}

For older patients or clients;

- Have you had any education or training to improve their exercise adherence? What are they?

- Are there any theories or research findings that you refer to when encouraging people to continue exercising?

- What kind of education do you think is needed to provide effective support? (What would you like to know to provide effective support?)

\section{Characteristics}

- Do you have a certified or specialized qualification provided by the Japanese Physical Therapy Association?

- Have you completed a master's or doctoral degree?

- How many years of clinical experience do you have?

Fig. 1. Interview guide.

\section{Data Analysis}

We used the Steps for Coding and Theorization (SCAT) method to analyze the transcripts in this study. ${ }^{19-21)}$ This method follows two stages, with the first stage consisting of four steps of coding: (1) picking up noteworthy words or phrases from the text, (2) paraphrasing, (3) explaining (2) using words outside the text, and (4) creating themes considering the context. The second stage consists of writing a sto- 
Table 1. Characteristics of participants $(n=15)$

\begin{tabular}{lr}
\hline Characteristic & $\mathrm{n}(\%)$ \\
\hline Highest academic degree & $2(13.3)$ \\
$\quad$ Diploma & $10(66.7)$ \\
Bachelor's & $3(20.0)$ \\
Master's & \\
Current practice & $13(86.7)$ \\
$\quad$ Hospital & $2(13.3)$ \\
Day service & \\
Years since qualified as a physical therapist & $10(66.7)$ \\
5-10 & $5(33.3)$ \\
11-15 & \\
Certified qualification* & $8(53.3)$ \\
Yes &
\end{tabular}

*Postgraduate certification includes cardiology, neurology, and musculoskeletal physical therapy.

ryline and a story. We used SCAT for its coding transparency and because it allowed the authors to verify the process. The analysis was primarily conducted by TA and was checked by $\mathrm{MN}$. When ambiguity was found in the analysis as part of the check, the matter was discussed to achieve a consensus.

\section{Ethical Consideration}

This study was approved by the International University of Health and Welfare Ethics Committee (approval number: 19Ifh-045). Written and oral informed consents were obtained from all participants.

\section{Trustworthiness}

To enhance the trustworthiness and credibility of the data analysis, we performed the data collection with interviews, field notes, and follow up interviews. The transcripts were reviewed by the participants. We conducted multiple checks on data analysis.

\section{RESULTS}

We recruited fifteen participants for this study. Three participants were interviewed a second time by telephone to discuss unclear points or to gain a deeper understanding. The median interview time was $60 \mathrm{~min}$ (range 51-75). Table 1 shows the participants' characteristics. Table 2 shows the main themes and subthemes that emerged, and Fig. 2 shows their association. A description of the themes and text excerpts are given below (ID: participant number - line number of the transcription). Those without an ID were spoken by the interviewer.

\section{EXPECTED RESULTS AS A HEALTHCARE PROFESSIONAL}

Physical therapists regarded their support in promoting older patients and clients to continue exercising as important. They understood the need to provide support that would have an impact lasting beyond the treatment session:

- "Well, time for the rehab session is limited in a day" (ID: $1-4)$.

- "Hmm. Older people tend to be less active, so I think it's important to get them to be active" (ID: $3-4$ ).

Most participants acknowledged that there were specific characteristics and roles to play for healthcare professionals to achieve the expected results:

- "That's right. Also, I think it's easier to teach them, simply because we can spend more time with them than other healthcare workers, such as nurses" (ID: 1-13).

- "Is it necessary for a physical therapist to take the lead in that kind of collaboration, too?"

"Yes, I think it is" (ID: 2-14).

- "Well, it's partly because I work at the hospital. But also, patients only have a limited amount of time for a physical therapy session. So, if they continue exercising in addition to that time, they'll be able to get discharged from the hospital sooner, and it is beneficial from a functional point as well, so I ask them to continue exercising" (ID: 6-4).

Table 2. Main themes and subthemes

\begin{tabular}{ll}
\hline Main theme & Subtheme \\
\hline $\begin{array}{l}\text { Expected results as a healthcare } \\
\text { professional }\end{array}$ & $\begin{array}{l}\text { Background, characteristics of the healthcare profession, roles, corporation, ex- } \\
\text { pected results }\end{array}$ \\
$\begin{array}{ll}\text { Clinical experience and continuing } \\
\text { professional development }\end{array}$ & $\begin{array}{ll}\text { Factors that decrease confidence, factors that increase confidence, career stage } \\
\text { Limited educational opportunities }\end{array}$ \\
& $\begin{array}{l}\text { Interest, postgraduate education in specific areas, clinical application of scientific } \\
\text { findings, clinical questions regarding support }\end{array}$ \\
\hline
\end{tabular}




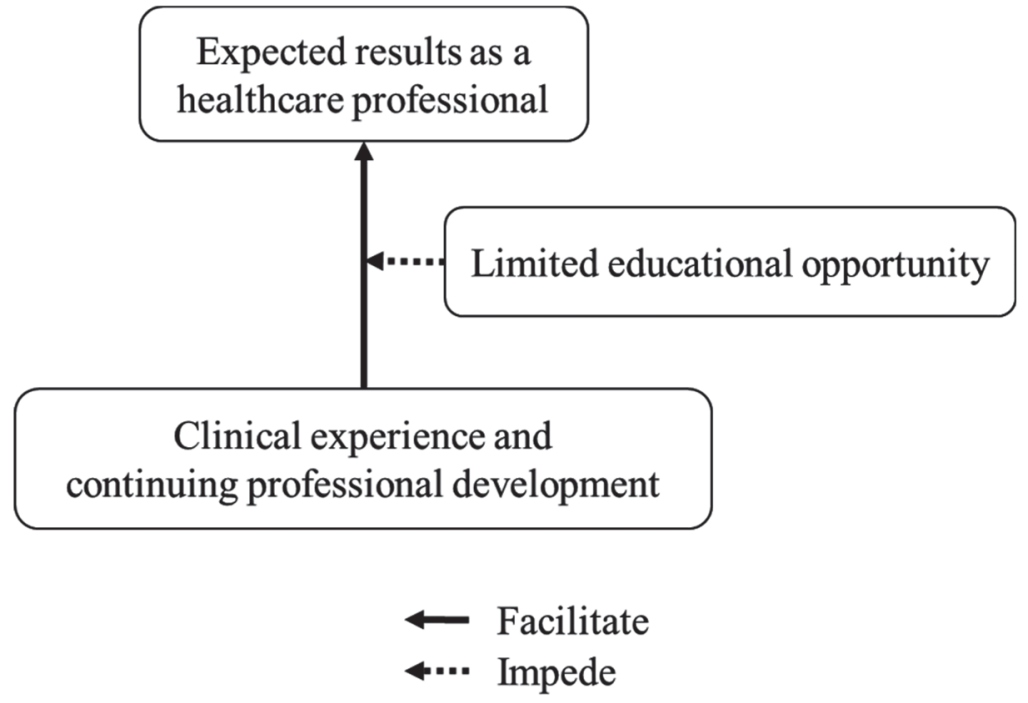

Fig. 2. Association of the main themes.

_ “... I mean, they may fall and hurt themselves and be hospitalized. I don't want them to be in that situation. I think exercise is important in preventing such situations" (ID: 11-4).

Also, participants understood that they sometimes required the help of other healthcare professionals, such as doctors, to provide efficient support.

_ “... I think that having a physical therapist or occupational therapist supporting patients and clients has some influence since they are the most involved in exercise interventions. I think the best way is probably for doctors, physicians, to tell them what to do" (ID: 15-8).

Overall, the physical therapist's attitude toward supporting the elderly to continue with exercise was positive, and they created the professional goal of providing effective support.

\section{CLINICAL EXPERIENCE AND CONTINUING PROFESSIONAL DEVELOPMENT}

The confidence of the participants in terms of supporting older patients to continue their exercise was low for several reasons. The main reason was the low rate of exercise adherence achieved compared with their professional expectations.

- "I'm confident in my teaching. But if you ask me if they are implementing it, I'm not sure; maybe only about $30 \%$ of them do. Yes, that's my impression" (ID: 3-10).

- "I've supported many patients in my career, but I don't think the success rate is $100 \%$. I think many of them did not successfully continue exercising" (ID: 4-14).

Several factors, such as clinical experience and continuing professional development increased the physical therapist's confidence in their support of older patients and clients:

- "Does this confidence seem to be increasing as your clinical experience increases?"

"Hmmm, yes. Well, that's true" (ID: 2-24).

- "I think I've gotten better at explaining the importance of exercise and persuading patients to keep to the regimen. And I phrase things better now than I did in the first 5 years of my career" (ID: 6-8).

Some stages were evident in the development of confidence:

- "As you said that you are confident earlier, is there something or some experience that makes you say that?"

"... When I think about the characteristics of the patients, I understand that it is difficult for them to memorize new things, and I can communicate and manage them in a more flexible manner. This helps them to continue exercising ...." (ID: 9-12).

- "I'm confident because now I can tell them what to expect" (ID: 15-24).

LIMITED EDUCATIONAL OPPORTUNITIES

The physical therapists recognized that there were few opportunities to systematically learn how to support their patients and clients and help them to continue exercising.

- "I think we can acquire great specialized knowledge, but to be honest, I don't think we've learned much about psychosocial aspects. For example, we don't really know how to improve the motivation of older patients. That is something we 
didn't learn much about during entry-level physical therapy education, so I'd like to know what's out there" (ID: 8-154).

Also, the interest of physical therapists in scientific findings showing how to support older patients was relatively low, and they did not prioritize spending time to search for specific research:

- “... Maybe if I looked it up, I could find some articles. But I never get around to it" (ID: 1-270).

- "Hmm. As I mentioned earlier, I don't have a lot of opportunities to read research articles on the continuation of exercise. Given the chance, I'd like to read about it" (ID: 6-192).

Some physical therapists applied specific scientific evidence in the clinical setting, but most of them still struggle to solve clinical questions raised by the difficulty of supporting older patients:

- "I always begin by giving my clients four pieces of information. This information includes verbal persuasion aimed at the care manager or the family. I also show them how other clients are exercising. That's something I consciously consider in my session" (ID: 5-162).

- "What is necessary to know to effectively support your patients?"

"I guess we have to include the psychology and pedagogy I mentioned earlier in our practice. The use of psychology and pedagogy, as well as the story I mentioned earlier about when the brain receives pleasant stimulations, is necessary" (ID: 12-194).

- "Some older people are active and exercise by themselves. When that happens, I like to know what environment they live in, so that I can apply this knowledge to my clients. I always want to know their environment and attitude" (ID: 13-172).

Therefore, physical therapists tend to rely on their own clinical experience as evidence for their intervention.

- "... I also wonder what we should do to encourage the patients according to their individuality. I'm providing support in my own style now...." (ID: 6-196).

\section{DISCUSSION}

In this qualitative study, we investigated the experiences and the perceptions of physical therapists relating to the support they provide to help older patients and clients to continue exercising. Our findings suggested that physical therapists considered this to be one of their most important roles. Their confidence in their ability to provide effective support varied depending on their clinical experience and postgraduate continuing professional development. However, the subjects felt that the current systematic education given on behavioral changes is insufficient for them to effectively support their older patients and clients. Therefore, the physical therapists generally relied on their colleague's or their own experience.

In this study, we revealed that the implementation of behavioral changes to improve exercise adherence in older patients and clients is not simply a part of the physical therapists' clinical practice, but that they also had certain expectations of results as healthcare professionals. A previous qualitative study indicated that physical therapists routinely include the promotion of physical activity in their practice. ${ }^{14)}$ Here, we investigated the physical therapists' professional attitudes. Their attitudes toward the support they provide to improve exercise adherence was positive, and they consider it to be an important goal to achieve from a healthcare provider's viewpoint.

Clinical experience and continuing professional development improved the physical therapists' confidence, although most of them showed low confidence levels because of the low exercise adherence rate of their patients and clients. A previous qualitative study also demonstrated that clinical experience and continuing professional development build physical therapists' perspectives on patient management in early knee osteoarthritis. ${ }^{22)}$ Other professionals, such as physicians, feel more confident in promoting physical activity than the participants of this study. ${ }^{12)}$ The content of promotion is associated with the provider's confidence, ${ }^{12}$ and the content provided by physicians is generally less detailed than that of physical therapists, which is to be expected, considering their professional roles. ${ }^{12)}$ Most physical therapists felt a lack of confidence, but this may be modified using appropriate training.

Despite high professional expectations and low levels of confidence in physical therapists, their learning opportunities to improve behavior change support were limited. According to previous studies, ${ }^{11,12)}$ the absence of available evidence and training can be barriers to providing effective support. We identified the application of specific scientific evidence in some practice; however, many physical therapists still struggled to answer various clinical questions about the support they give. They reported little interest in the answers to these types of questions. The promotion of physical activity is one of the physical therapist's important roles, ${ }^{13)}$ but the current systematic education on using scientific evidence on behavior change techniques for the older population may be inadequate. It is critical to investigate whether the implementation of a more adequate level of systematic edu- 
cation on supporting behavior change might contribute to the improvement of long-term exercise adherence. The learning activities aimed at improving physical therapists' practice should include accessible and evidence-based resources. ${ }^{23)}$

This study suggests that to improve the support of behavior change in the older population, we should consider the provider's opportunities to access beneficial evidence. Compared to other factors, such as the contents of the exercise program and personal factors, ${ }^{24)}$ the provider's impact on exercise adherence has not adequately been investigated. Various pieces of scientific evidence have shown how to use behavior change techniques to improve exercise adherence, but clinicians struggle to use them. Both entry-level and postgraduate physical therapists should learn how to integrate scientific evidence into clinical practice.

One of the strengths of this study is that we included participants from different clinical settings and therefore provided more in-depth understanding. Nonetheless, this study has some limitations. We recruited the participants using purposive sampling in Japan. We included only male participants because the interviewer was male. However, this study had an exploratory purpose, and our findings can be used as a hypothesis for future study.

Physical therapists may need more adequate systematic educational opportunities to improve the behavioral change techniques used to support long-term exercise adherence in the older population. These opportunities should enhance their confidence and lead to improved clinical results. In future studies, the efficacy of educational interventions aimed at increasing the provider's confidence and improving patient outcomes should be examined.

\section{ACKNOWLEDGMENTS}

We would like to thank all the participants for their contribution to this study.

\section{CONFLICTS OF INTEREST}

The authors declare that there are no conflicts of interest.

\section{REFERENCES}

1. Guthold R, Stevens GA, Riley LM, Bull FC: Worldwide trends in insufficient physical activity from 2001 to 2016: a pooled analysis of 358 population-based surveys with 1.9 million participants. Lancet Glob Health 2018;6:e1077-e1086. DOI:10.1016/S2214109X(18)30357-7, PMID:30193830

2. Marengoni A, Angleman S, Melis R, Mangialasche F, Karp A, Garmen A, Meinow B, Fratiglioni L: Aging with multimorbidity: a systematic review of the literature. Ageing Res Rev 2011;10:430-439. DOI:10.1016/j. arr.2011.03.003, PMID:21402176

3. Covinsky KE, Palmer RM, Fortinsky RH, Counsell SR, Stewart AL, Kresevic D, Burant CJ, Landefeld CS: Loss of independence in activities of daily living in older adults hospitalized with medical illnesses: increased vulnerability with age. J Am Geriatr Soc 2003;51:451-458. DOI:10.1046/j.15325415.2003.51152.x, PMID:12657063

4. Howe TE, Rochester L, Neil F, Skelton DA, Ballinger $\mathrm{C}$ : Exercise for improving balance in older people. Cochrane Database Syst Rev 2011;11:CD004963. DOI:10.1002/14651858.CD004963.pub3, PMID:22071817

5. Northey JM, Cherbuin N, Pumpa KL, Smee DJ, Rattray B: Exercise interventions for cognitive function in adults older than 50: a systematic review with meta-analysis. Br J Sports Med 2018;52:154-160. DOI:10.1136/bjsports-2016-096587, PMID:28438770

6. Hughes KJ, Salmon N, Galvin R, Casey B, Clifford AM: Interventions to improve adherence to exercise therapy for falls prevention in community-dwelling older adults: systematic review and meta-analysis. Age Ageing 2019;48:185-195. DOI:10.1093/ageing/afy164, PMID:30358800

7. Nyman SR, Adamczewska N, Howlett N: Systematic review of behaviour change techniques to promote participation in physical activity among people with dementia. Br J Health Psychol 2018;23:148-170. DOI:10.1111/bjhp.12279, PMID:28980370

8. Kunstler BE, Cook JL, Freene N, Finch CF, Kemp JL, O'Halloran PD, Gaida JE: Physiotherapists use a small number of behaviour change techniques when promoting physical activity: a systematic review comparing experimental and observational studies. J Sci Med Sport 2018;21:609-615. DOI:10.1016/j. jsams.2017.10.027, PMID:29233466 
9. Kunstler BE, Cook JL, Freene N, Finch CF, Kemp JL, O'Halloran PD, Gaida JE: Physiotherapist-led physical activity interventions are efficacious at increasing physical activity levels. Clin J Sport Med 2018;28:304315. DOI:10.1097/JSM.0000000000000447, PMID:29064864

10. Tang MY, Smith DM, McSharry J, Hann M, French DP: Behavior change techniques associated with changes in postintervention and maintained changes in self-efficacy for physical activity: a systematic review with meta-analysis. Ann Behav Med 2019;53:801-815. DOI:10.1093/abm/kay090, PMID:30534971

11. Alageel S, Gulliford MC, McDermott L, Wright AJ: Implementing multiple health behaviour change interventions for cardiovascular risk reduction in primary care: a qualitative study. BMC Fam Pract 2018;19:171. DOI:10.1186/s12875-018-0860-0, PMID:30376826

12. Hébert ET, Caughy MO, Shuval K: Primary care providers' perceptions of physical activity counselling in a clinical setting: a systematic review. Br J Sports Med 2012;46:625-631. DOI:10.1136/bjsports-2011-090734, PMID:22711796

13. Verhagen E, Engbers L: The physical therapist's role in physical activity promotion. Br J Sports Med 2008;43:99-101. DOI:10.1136/bjsm.2008.053801, PMID:18838405

14. Lowe A, Littlewood C, McLean S: Understanding physical activity promotion in physiotherapy practice: a qualitative study. Musculoskelet Sci Pract 2018;35:1-7. DOI:10.1016/j.msksp.2018.01.009, PMID:29413948

15. O'Brien BC, Harris IB, Beckman TJ, Reed DA, Cook DA: Standards for reporting qualitative research: a synthesis of recommendations. Acad Med 2014;89:12451251. DOI:10.1097/ACM.0000000000000388, PMID:24979285

16. Kim H, Sefcik JS, Bradway C: Characteristics of qualitative descriptive studies: a systematic review. Res Nurs Health 2017;40:23-42. DOI:10.1002/nur.21768, PMID:27686751
17. Denzin N, Lincoln Y: Strategies of Qualitative Inquiry. Los Angeles: SAGE, 2008.

18. Cowell I, O’Sullivan P, O’Sullivan K, Poyton R, McGregor A, Murtagh G: Perceptions of physiotherapists towards the management of non-specific chronic low back pain from a biopsychosocial perspective: a qualitative study. Musculoskelet Sci Pract 2018;38:113-119. DOI:10.1016/j.msksp.2018.10.006, PMID:30423526

19. Otani T: "SCAT" A qualitative data analysis method by four-step coding: easy startable and small dataapplicable process of theorization. Bull Grad School Educ Human Dev Nagoya Univ 2007;54:27-44.

20. Goto A, Rudd RE, Lai AY, Yoshida K, Suzuki Y, Halstead DD, Yoshida-Komiya H, Reich MR: Leveraging public health nurses for disaster risk communication in Fukushima City: a qualitative analysis of nurses' written records of parenting counseling and peer discussions. BMC Health Serv Res 2014;14:129. DOI:10.1186/1472-6963-14-129, PMID:24642079

21. Hayashi M, Son D, Onishi H, Eto M: Contribution of short-term global clinical health experience to the leadership competency of health professionals: a qualitative study. BMJ Open 2019;9:e027969. DOI:10.1136/ bmjopen-2018-027969, PMID:31272978

22. MacKay C, Hawker GA, Jaglal SB: How do physiotherapists approach management of people with early knee osteoarthritis? A qualitative study. Phys Ther 2020;100:295-306. DOI:10.1093/ptj/pzz164, PMID:31722426

23. Leahy E, Chipchase L, Calo M, Blackstock FC: Which learning activities enhance physical therapist practice? Part 2: Systematic review of qualitative studies and thematic synthesis. Phys Ther 2020;100:1484-1501. DOI:10.1093/ptj/pzaa108, PMID:32529234

24. Picorelli AM, Pereira LS, Pereira DS, Felício D, Sherrington C: Adherence to exercise programs for older people is influenced by program characteristics and personal factors: a systematic review. J Physiother 2014;60:151-156. DOI:10.1016/j.jphys.2014.06.012, PMID:25092418 